\title{
A review of the pharmacoeconomics of eletriptan for the acute treatment of migraine
}

This article was published in the following Dove Press journal:

International Journal of General Medicine

12 January 2015

Number of times this article has been viewed

\author{
Rahul Bhambri' \\ Jack Mardekian' \\ Larry Z Liu',2 \\ Edward Schweizer ${ }^{3}$ \\ Elodie Ramos'
}

'Pfizer, Inc., ${ }^{2}$ Weill Medical College of Cornell University, New York, NY, USA; ${ }^{3}$ Paladin Consulting Group, Princeton, NJ, USA
Correspondence: Rahul Bhambri Pfizer Inc., 235 E42nd Street, New York, NY 10017, USA

$\mathrm{Tel}+$ I 2127335151

Email rahul.bhambri@pfizer.com
Abstract: Migraine is a commonly occurring, chronic disorder that can cause significant disability. Eletriptan, a selective serotonin 5-hydroxytryptamine 1 receptor subtype B/D (5-HT $1 \mathrm{~B} / 1 \mathrm{D})$ agonist, is a clinically effective treatment for moderate to severe migraine. The objective of this literature review was to summarize the available data on the pharmacoeconomics of eletriptan relative to other triptans. Articles meeting the following three criteria were included in the review: 1) contained pharmacoeconomic data on a marketed dose of eletriptan; 2) included data on at least one other comparator triptan; and 3) was in English. A MEDLINE ${ }^{\circledR}$ search yielded a total of eight studies (from the European Union [ $n=5]$ and from the USA [ $=3]$ ) across multiple regions. Seven of the studies examined the pharmacoeconomics of eletriptan relative to other triptans, and a further study examined the health care costs of eletriptan $40 \mathrm{mg}$ versus sumatriptan 100 $\mathrm{mg}$. Eletriptan $40 \mathrm{mg}$ was among a group of triptans, including rizatriptan $10 \mathrm{mg}$ and almotriptan $12.5 \mathrm{mg}$, demonstrating the greatest cost-effectiveness. This result held across different definitions of efficacy ( 2 hours pain-free, sustained pain-free, and sustained pain-free with no adverse events) and also held when cost-effectiveness models accounted for second doses and use of rescue medication, management of adverse events, and productivity loss, in addition to drug acquisition costs. Only limited head-to-head comparator data were available. The majority of pharmacoeconomic studies utilized the same set of efficacy and/or tolerability data, and indirect costs were rarely included despite the fact that the majority of per capita migraine costs are attributable to indirect costs. In summary, although the market is now dominated by generics, eletriptan $40 \mathrm{mg}$ is among the most clinically and cost-effective oral triptans available for the management of acute migraine. Increased effectiveness/efficacy of eletriptan may necessitate a lesser need for other migraine treatments and/or switching to other triptans.

Keywords: oral triptans, cost-effectiveness, literature search

\section{Introduction}

Acute migraine is a commonly occurring chronic, idiopathic headache disorder that is characterized by moderate to severe headache pain that is usually unilateral and throbbing. ${ }^{1}$ Migraine pain can be exacerbated by physical activity and is often accompanied by other symptoms, including nausea, vomiting, and sensitivity to light (photophobia) and sound (phonophobia). ${ }^{1}$ The typical duration of an attack ranges from 4-72 hours (median, 18 hours). ${ }^{1}$ In approximately $10 \%-20 \%$ of patients, the onset of headache pain is preceded by transient focal neurological symptoms, most commonly visual disturbances, referred to as aura. ${ }^{1-3}$ Median migraine attack frequency is once a month, but at least $25 \%$ of patients report three or more headache days per month. ${ }^{4}$ Furthermore, migraine can cause notable disability in some sufferers and is 
a major cause of workplace absenteeism and/or decreased productivity among workers. ${ }^{5,6}$

Migraine occurs more commonly in women than men. ${ }^{4}$ For example, in the USA, migraine is estimated to have a lifetime prevalence of approximately $18 \%$ in females and $6 \%$ in males. Migraine markedly reduces work productivity, with $24 \%$ of sufferers missing at least a day of work every 3 months, and $45 \%$ having at least a day of reduced productivity every 3 months. ${ }^{2,7}$ Migraine attacks represent approximately $3 \%$ of all emergency department visits in the USA. ${ }^{8}$

Triptans are usually the preferred treatment for moderate to severe migraine attacks or mild to moderate attacks not responding to analgesics or anti-inflammatory drugs. ${ }^{9}$ They are potent selective serotonin $5-\mathrm{HT}_{1 \mathrm{~B} / 1 \mathrm{D}}$ receptor agonists. Although, the mechanism of action of triptans has not yet been established, they are hypothesized to work by various mechanisms, including vasoconstriction, inhibition of release of nociceptive neuropeptides from trigeminal pain afferents (substance $\mathrm{P}$ and calcitonin gene-related peptide), and inhibitory modulation of various central nervous system pathways (including the trigeminal nucleus caudalis, periaqueductal gray, and thalamus). ${ }^{10}$

Sumatriptan was the first triptan to be marketed, followed by a further six triptans (almotriptan, eletriptan, frovatriptan, naratriptan, rizatriptan, and zolmitriptan), which exhibit improved pharmacokinetic properties. Although they can be relatively expensive, ${ }^{11}$ triptans may improve quality of life, with treatment costs being offset by savings achieved by reduced demands on health care services and increased work productivity. Most triptans are currently available in cheaper generic forms (Table 1). In a meta-analysis of studies, all triptans relieved some pain within 2 hours in 49\%-69\% of individuals who had moderate to severe migraine (Table 2), with eletriptan $40 \mathrm{mg}$ and rizatriptan $10 \mathrm{mg}$ providing the greatest relief. ${ }^{12}$

Here, we review the literature with respect to the socioeconomic burden of migraine, and we discuss the clinical

Table I Branded and generic oral triptans

\begin{tabular}{lllll}
\hline $\begin{array}{l}\text { Generic } \\
\text { name }\end{array}$ & $\begin{array}{l}\text { Recommended } \\
\text { oral dose } \mathbf{( m g )}\end{array}$ & $\begin{array}{l}\text { Brand } \\
\text { name }\end{array}$ & Manufacturer & $\begin{array}{l}\text { Generic } \\
\text { version }\end{array}$ \\
\hline Almotriptan & 12.5 & Axert $^{\circledR}$ & $\begin{array}{l}\text { Almirall- } \\
\text { Prodesfarma }\end{array}$ & No \\
Eletriptan & $20,40,80$ & Relpax $^{\circledR}$ & Pfizer & No \\
Frovatriptan & 2.5 & Frova $^{\circledR}$ & Vernalis & No \\
Naratriptan & 2.5 & Amerge $^{\circledR}$ & GSK & Yes \\
Rizatriptan & 5,10 & Maxalt $^{\circledR}$ & Merck & Yes \\
Sumatriptan & $25,50,100$ & Imitrex $^{\circledR}$ & GSK & Yes \\
Zolmitriptan & $2.5,5$ & Zomig $^{\circledR}$ & AstraZeneca & Yes \\
\hline
\end{tabular}

profile and pharmacoeconomic data of eletriptan for the acute treatment of migraine.

\section{Socioeconomic burden of migraine}

The costs of migraine to society are due to the usage of health care resources and lost work productivity. Moreover, negative impact on quality of life experienced by migraine sufferers makes the condition costly to individuals as well as to society. The overall economic burden of productivity losses associated with migraine in the USA exceeds that of chronic conditions of heart disease, diabetes, asthma, and depression. ${ }^{13}$ The indirect costs of migraine, such as lost days from work and reduced productivity, are hugely uncertain but are considered to exceed direct medical costs for medications, office, clinic or emergency department visits, outpatient services, laboratory and diagnostic tests, and the treatment of medication-related adverse effects. One reason cited for the heavier burden imposed by indirect costs is that migraine prevalence peaks when patients are at the height of their work productivity (aged 25-44 years). ${ }^{14,15}$

Different studies estimate that in the general population, the number of working days missed due to migraine per year per migraine sufferer ranges from 0.5-6.7 days. ${ }^{16}$ For example, one large cross-sectional survey conducted in nine countries (Finland, Germany, Greece, Italy, Norway, Spain, Sweden, the Netherlands, and Israel) in female migraine sufferers aged 18-35 years over a 6-month period, reported a mean absence from work or school of 3.8 days per year due to migraine. ${ }^{17}$ Further, the same study estimated that sufferers were unable to function properly at work or school for an additional 8.6 days per year because of migraine. ${ }^{17}$

In the USA, the total costs of migraine (using 1992-1999 values) were estimated to be approximately $\$ 1$ billion in direct costs annually and \$4-\$17 billion in indirect costs annually. ${ }^{16,18}$ The recent Eurolight project, a survey conducted in nine countries of the European Union, estimated societal losses attributable to all headache disorders (direct and indirect costs) at well over $€ 100$ billion per year, ${ }^{19}$ with more than $90 \%$ indirectly attributable to lost productivity. In another national estimate of the annual cost of migraine, $\mathrm{Hu}$ et $\mathrm{al}^{18}$ estimated that direct medical costs were responsible for $6.8 \%$ of total costs in men and $7.3 \%$ in women. The percent of the total cost attributable to drug costs was $1.6 \%$ in men and $2.2 \%$ in women. Other studies yield similar results, with direct medical costs consistently estimated to contribute less than $20 \%$ to the overall cost burden of migraine. ${ }^{20}$ 
Table 2 Meta-analysis of the effectiveness of oral triptans, shown in order of effectiveness for 2-hour pain relief

\begin{tabular}{lllll}
\hline $\begin{array}{l}\text { Triptan and dose (maximum } \\
\text { 24-hour dosing) }\end{array}$ & $\begin{array}{l}\text { 2-hour } \\
\text { pain relief }\end{array}$ & $\begin{array}{l}\text { 2 hours } \\
\text { pain-free }\end{array}$ & $\begin{array}{l}\text { Sustained pain-free } \\
\text { plus no adverse events }\end{array}$ & \begin{tabular}{l} 
Recurrence \\
\hline Eletriptan $40 \mathrm{mg}(80 \mathrm{mg})$
\end{tabular} \\
Rizatriptan $10 \mathrm{mg}(30 \mathrm{mg})$ & $69 \%$ & $39 \%$ & $21 \%$ & $26 \%$ \\
Zolmitriptan $5 \mathrm{mg}(10 \mathrm{mg})$ & $65 \%$ & $37 \%$ & $16 \%$ & $38 \%$ \\
Sumatriptan $100 \mathrm{mg}(200 \mathrm{mg})$ & $62 \%$ & $33 \%$ & $14 \%$ & $28 \%$ \\
Almotriptan $12.5 \mathrm{mg}(25 \mathrm{mg})$ & $61 \%$ & $32 \%$ & $15 \%$ & $31 \%$ \\
Naratriptan $2.5 \mathrm{mg}(5 \mathrm{mg})$ & $56 \%$ & $25 \%$ & $13 \%$ & $33 \%$ \\
Frovatriptan $2.5 \mathrm{mg}$ (7.5 mg) & $49 \%$ & $18 \%$ & - & $20 \%$ \\
Placebo & - & - & $4 \%$ & $37 \%$ \\
\hline
\end{tabular}

Note: *No head-to-head trials.

Adapted with permission from Asseburg C, Peura P, Oksanen T, et al. Cost-effectiveness of oral triptans for acute migraine: mixed treatment comparison. Int J Technol Assess Health Care. 2012;28(4):382-389; online Supplementary materials, Table 2.'2

\section{Clinical profile of eletriptan}

Eletriptan, an orally administered, lipophilic, highly selective serotonin 5-HT ${ }_{1 \mathrm{~B} / \mathrm{D}}$ receptor agonist, has an established efficacy profile for the acute treatment of migraine in subjects experiencing moderate to severe migraine attacks. ${ }^{3}$ Eletriptan $40 \mathrm{mg}$ has shown superiority, based on results from head-to-head comparator studies versus sumatriptan $50 \mathrm{mg}$ and $100 \mathrm{mg},{ }^{21-23}$ naratriptan $2.5 \mathrm{mg},{ }^{24}$ and zolmitriptan $2.5 \mathrm{mg} .{ }^{25}$ Based on the results of switch studies, eletriptan $40 \mathrm{mg}$ has also demonstrated significant efficacy in migraine sufferers who did not respond to treatment with either sumatriptan or rizatriptan, ${ }^{8,26}$ or to nonsteroidal anti-inflammatory drugs. ${ }^{27-29}$

In two separate meta-analyses, eletriptan was found to be among the most effective of all marketed triptans. ${ }^{30,31}$ In the first meta-analysis, rizatriptan $10 \mathrm{mg}$, eletriptan $80 \mathrm{mg}$, and almotriptan $12.5 \mathrm{mg}$ were the most likely triptans to provide consistent success. ${ }^{30}$ The results of the most recent meta-analysis, based on a sophisticated multiple-treatment comparison methodology, showed that eletriptan $40 \mathrm{mg}$ treatment had the highest probability, compared with other triptans, of patients being pain-free at 2 hours (Figure 1A), followed by rizatriptan $10 \mathrm{mg}$ and then zolmitriptan $12.5 \mathrm{mg}$; eletriptan $40 \mathrm{mg}$ also had the highest probability of patients being pain-free at 24 hours (Figure 1B), followed by zolmitriptan $12.5 \mathrm{mg} .{ }^{31}$

Eletriptan is generally safe and well tolerated. Adverse events rates are low for eletriptan $40 \mathrm{mg}$, and events are typically rated as mild or moderate. The most frequent adverse events for eletriptan $40 \mathrm{mg}$ (versus placebo) are dizziness ( $6 \%$ versus $3 \%$, respectively), somnolence ( $6 \%$ versus $4 \%$, respectively), and asthenia (5\% versus $3 \%$, respectively). ${ }^{32}$

\section{Pharmacoeconomic analysis of eletriptan}

The pharmacoeconomics of eletriptan were studied following a systematic literature review. Studies for inclusion in the review were identified through a MEDLINE ${ }^{\circledR}$ search using the following key words: "eletriptan", "triptan", "migraine", "cost-effectiveness", "cost utility", "cost", "cost-benefit", "cost control", "economic evaluation", "drug cost", "productivity", and "pharmacoeconomic". Identified articles were reviewed to determine whether they met the following three criteria: 1) the article contained cost-effectiveness or associated health care cost data on eletriptan; 2) the article included data on at least one other comparator triptan; and 3) the article was in English.

Applying these criteria to the search resulted in a final set of seven pharmacoeconomic studies (Table 3) and one health care cost study. ${ }^{12,33-39}$ Five of the pharmacoeconomic studies incorporated only efficacy data into cost-effectiveness ratios; three of the studies defined successful outcome in terms of being both pain-free and with no recorded adverse events. Only two of the studies included analyses of the effect of treatment on the indirect costs of migraine, and these analyses were limited..$^{12,20}$ Six of the included studies were financed by manufacturers, ${ }^{33-38}$ and two were independent studies. ${ }^{12,39}$ The efficacy data used in most of the studies originated from a previous meta-analysis by Ferrari et al. ${ }^{30}$ Most studies were conducted before patentexpiration of the original brand products; therefore, only the most recent report considered generic prices. ${ }^{12}$ Study results are shown in Table 4 and are reviewed individually.

In 2004, Belsey ${ }^{33}$ conducted a comprehensive cost-effectiveness analysis of all seven triptans in the treatment of an acute migraine attack, using data from a meta-analysis of 37 randomized, placebo-controlled trials studies conducted in six countries (UK, Germany, Netherlands, Italy, USA, and Canada). The effect sizes were numbers needed to treat based on the proportion of patients who were pain-free at 2 hours postdose in both treatment and placebo groups. ${ }^{33}$ Incremental cost-effectiveness was compared for sumatriptan $100 \mathrm{mg}$, which was the first and most widely prescribed oral triptan. Rizatriptan $10 \mathrm{mg}$ and eletriptan $40 \mathrm{mg}$ and $80 \mathrm{mg}$ were the most cost-effective oral triptans 


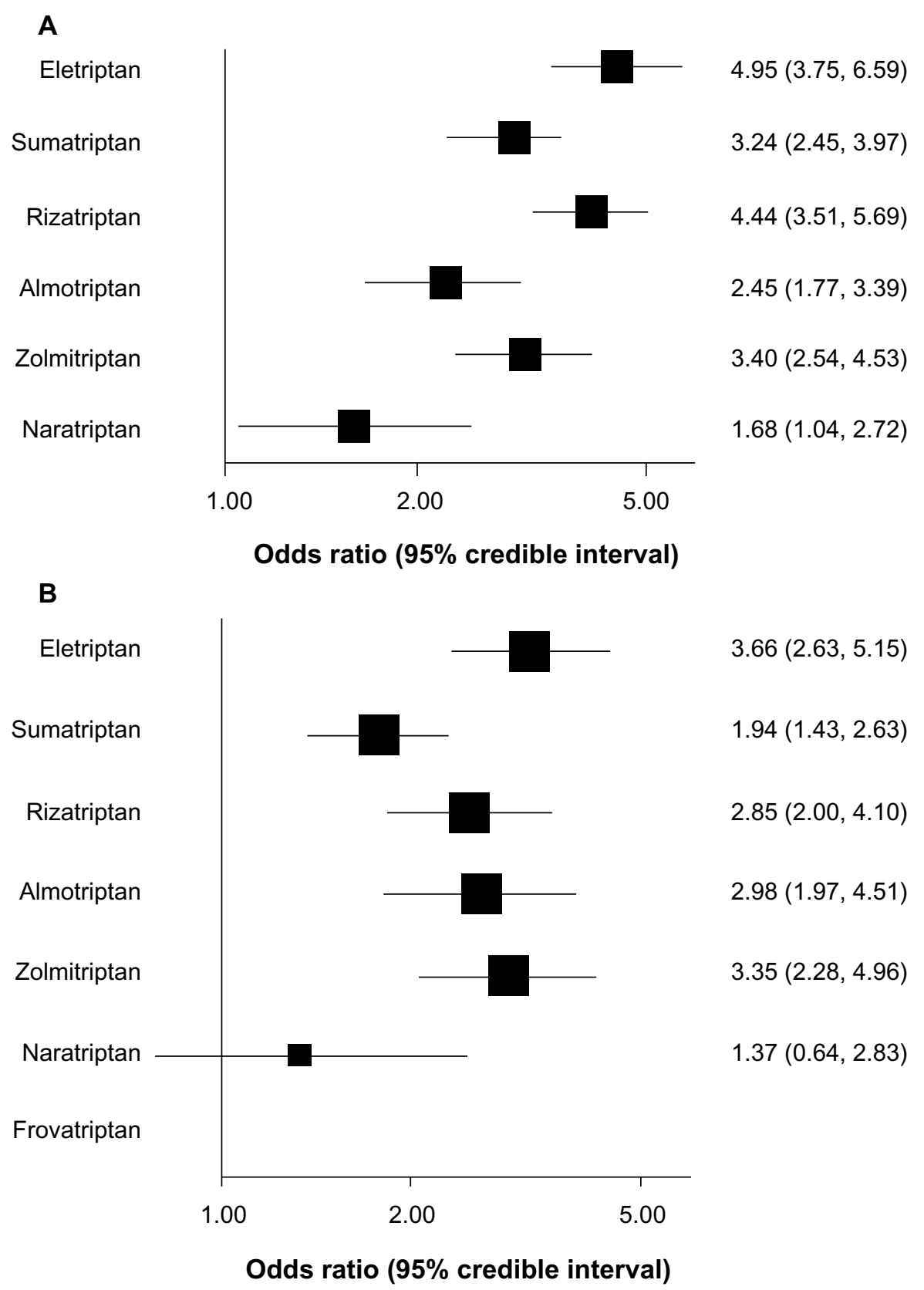

Figure I Forest plots of the primary multiple treatment comparison meta-analysis results.

Notes: (A) Pain-free response at 2 hours, for triptans versus placebo. (B) Sustained pain-free response at 24 hours, for triptans versus placebo. Reproduced from Thorlund K, Mills EJ, Wu P et al. Comparative efficacy of triptans for the abortive treatment of migraine: A multiple treatment comparison meta-analysis. Chephalagia. 20 I4;34(4):258-267.31

with respect to the outcome of pain-free at 2 hours postdose (Table 4).$^{33}$ Overall, rizatriptan $10 \mathrm{mg}$ exhibited the most favorable absolute cost-effectiveness ratio in all six countries included in the analysis. ${ }^{33}$ In a comparison with sumatriptan $100 \mathrm{mg}$, rizatriptan $10 \mathrm{mg}$ and eletriptan $40 \mathrm{mg}$ were consistently the most cost-effective therapeutic options in five of the six countries examined. ${ }^{33}$ This study had several limitations. For example, the analysis was informal and only considered drug acquisition costs for branded products. In addition, the costs of extra doses/rescue medication were not considered.
In 2005, in a meta-analysis, Perfetto et $\mathrm{al}^{36}$ evaluated the cost-effectiveness of six oral triptans (almotriptan, eletriptan, naratriptan, rizatriptan, sumatriptan, and zolmitriptan), using clinical data from the previously published meta-analysis conducted by Ferrari et al, ${ }^{30}$ examining the total costs of triptans for treating 100 migraine attacks, as well as the costs per successfully treated patient. Two-hour response, pain-free response, and recurrence rate were used to estimate the number of doses that were used for treatment of each success and failure. ${ }^{36}$ Total triptan cost was 
Table 3 Characteristics of pharmacoeconomic studies involving triptans

\begin{tabular}{|c|c|c|c|c|c|}
\hline Study & Triptans & Funding source & $\begin{array}{l}\text { Primary efficacy } \\
\text { measure }\end{array}$ & $\begin{array}{l}\text { Source of efficacy and } \\
\text { tolerability data }\end{array}$ & Cost variable \\
\hline Belsey $^{33}$ & $\begin{array}{l}\text { Almotriptan } \\
\text { Eletriptan } \\
\text { Frovatriptan } \\
\text { Naratriptan } \\
\text { Rizatriptan } \\
\text { Sumatriptan } \\
\text { Zolmitriptan }\end{array}$ & Merck and Co Inc. & 2 hours pain-free & $\begin{array}{l}\text { Meta-analysis of } \\
37 \text { placebo-controlled trials }\end{array}$ & Drug acquisition \\
\hline Perfetto et $\mathrm{al}^{36}$ & $\begin{array}{l}\text { Almotriptan } \\
\text { Eletriptan } \\
\text { Naratriptan } \\
\text { Rizatriptan } \\
\text { Sumatriptan } \\
\text { Zolmitriptan }\end{array}$ & Pfizer & Sustained pain-free & Ferrari et $\mathrm{al}^{30}$ meta-analysis & Drug acquisition \\
\hline Slof et $\mathrm{al}^{37}$ & $\begin{array}{l}\text { Almotriptan } \\
\text { Eletriptan } \\
\text { Naratriptan } \\
\text { Rizatriptan } \\
\text { Sumatriptan } \\
\text { Zolmitriptan }\end{array}$ & $\begin{array}{l}\text { Almirall } \\
\text { Prodesfarma }\end{array}$ & Sustained pain-free & Ferrari et $\mathrm{al}^{30}$ meta-analysis & $\begin{array}{l}\text { Drug acquisition; management } \\
\text { of chest-related and CNS- } \\
\text { related adverse events }\end{array}$ \\
\hline Mullins et $\mathrm{al}^{35}$ & $\begin{array}{l}\text { Almotriptan } \\
\text { Eletriptan } \\
\text { Naratriptan } \\
\text { Rizatriptan } \\
\text { Sumatriptan } \\
\text { Zolmitriptan }\end{array}$ & Pfizer & Sustained pain-free & Ferrari et $\mathrm{al}^{30}$ meta-analysis & Drug acquisition \\
\hline $\begin{array}{l}\text { Kelman and } \\
\text { Von Seggern }{ }^{34}\end{array}$ & $\begin{array}{l}\text { Almotriptan } \\
\text { Eletriptan } \\
\text { Naratriptan } \\
\text { Rizatriptan } \\
\text { Sumatriptan } \\
\text { Zolmitriptan }\end{array}$ & $\begin{array}{l}\text { Ortho-McNeil } \\
\text { Pharmaceuticals Inc }\end{array}$ & $\begin{array}{l}\text { Sustained pain-free } \\
\text { plus no adverse events }\end{array}$ & Ferrari et $\mathrm{al}^{30}$ meta-analysis & Drug acquisition \\
\hline $\begin{array}{l}\text { Ramsberg and } \\
\text { Henriksson }{ }^{39}\end{array}$ & $\begin{array}{l}\text { Almotriptan } \\
\text { Eletriptan } \\
\text { Rizatriptan } \\
\text { Sumatriptan } \\
\text { Zolmitriptan }\end{array}$ & Independent & $\begin{array}{l}\text { Sustained pain-free } \\
\text { plus no adverse events }\end{array}$ & Ferrari et $\mathrm{al}^{30}$ meta-analysis & $\begin{array}{l}\text { Drug acquisition; lost } \\
\text { productivity }\end{array}$ \\
\hline Asseburg et $\mathrm{al}^{12}$ & $\begin{array}{l}\text { Almotriptan } \\
\text { Eletriptan } \\
\text { Frovatriptan } \\
\text { Naratriptan } \\
\text { Rizatriptan } \\
\text { Sumatriptan } \\
\text { Zolmitriptan }\end{array}$ & Independent & $\begin{array}{l}\text { Sustained pain-free } \\
\text { plus no adverse events }\end{array}$ & $\begin{array}{l}\text { Meta-analysis of } 56 \\
\text { publications ( } 58 \text { studies) }\end{array}$ & $\begin{array}{l}\text { Drug acquisition; lost } \\
\text { productivity }\end{array}$ \\
\hline Wells et $\mathrm{al}^{38}$ & $\begin{array}{l}\text { Eletriptan } \\
\text { Sumatriptan }\end{array}$ & Pfizer & Sustained pain-free & $\begin{array}{l}\text { One comparator trial: } \\
\text { Sandrini et } \mathrm{al}^{23}\end{array}$ & $\begin{array}{l}\text { Drug acquisition; second } \\
\text { dose; rescue medications }\end{array}$ \\
\hline
\end{tabular}

Abbreviation: CNS, central nervous system.

calculated by using the average wholesale price per dose, less $15 \%$ for use of a nongeneric triptan. ${ }^{36}$ Overall, eletrip$\tan 40 \mathrm{mg}$ had the lowest total triptan cost for treating 100 migraine attacks $(\$ 1,560)$, followed by zolmitriptan $2.5 \mathrm{mg}$ $(\$ 1,629)$, and almotriptan $(\$ 1,670) .{ }^{36}$ Eletriptan $40 \mathrm{mg}$ also had the lowest cost per successfully treated patient (\$56.39) (Table 4). ${ }^{36}$ Naratriptan $2.5 \mathrm{mg}$ had the greatest total cost for treating 100 patients $(\$ 1,945)$, as well as the greatest cost for successfully treating a single patient (\$111.44) (Table 4). ${ }^{36}$ This study, again, had several key limitations; it was an informal analysis where only the costs of drug acquisition were taken into consideration, and the costs of rescue medication were not calculated.

A further study conducted in Spain examined the costeffectiveness of six marketed triptans (almotriptan, eletriptan, naratriptan, rizatriptan, sumatriptan, and zolmitriptan). ${ }^{37}$ 
Table 4 Pharmacoeconomic studies of triptans in the treatment of migraine

\begin{tabular}{|c|c|c|c|c|c|c|c|}
\hline Study & $\begin{array}{l}\text { Almotriptan } \\
\text { 1 } 2.5 \mathrm{mg}\end{array}$ & $\begin{array}{l}\text { Eletriptan } \\
40 \mathrm{mg}\end{array}$ & $\begin{array}{l}\text { Naratriptan } \\
2.5 \mathrm{mg}\end{array}$ & $\begin{array}{l}\text { Rizatriptan } \\
10 \mathrm{mg}\end{array}$ & $\begin{array}{l}\text { Sumatriptan } \\
100 \mathrm{mg}\end{array}$ & $\begin{array}{l}\text { Zolmitriptan } \\
5 \mathrm{mg}\end{array}$ & $\begin{array}{l}\text { Frovatriptan } \\
2.5 \mathrm{mg}\end{array}$ \\
\hline \multicolumn{8}{|l|}{ Belsey ${ }^{33, a}$} \\
\hline USA & $\$ 73.40$ & $\$ 52.80$ & $\$ 140.10$ & $\$ 47.30$ & $\$ 68.10$ & $\$ 76.60$ & $\$ 153.50$ \\
\hline UK & $\$ 21.83$ & $\$ 22.20$ & $\$ 45.81$ & $\$ 19.82$ & $\$ 53.50$ & $\$ 45.89$ & $\$ 51.42$ \\
\hline Germany & $\$ 28.70$ & $\$ 26.10$ & $\$ 49.20$ & $\$ 21.90$ & $\$ 45.60$ & $\$ 31.20$ & $\$ 45.00$ \\
\hline Italy & $\$ 20.30$ & $\$ 21.10$ & - & $\$ 18.20$ & $\$ 39.30$ & $\$ 41.60$ & - \\
\hline The Netherlands & $\$ 27.80$ & $\$ 25.00$ & $\$ 41.20$ & $\$ 19.00$ & $\$ 50.10$ & $\$ 49.00$ & - \\
\hline Perfetto et $a^{36, b}$ & $\$ 90.52$ & $\$ 56.39$ & $\$ 111.44$ & $\$ 82.53$ & $\$ 85.29$ & $\$ 84.93$ & - \\
\hline Slof et al ${ }^{37, c}$ & $€ 19.97$ & $€ 25.85$ & $€ 22.86$ & $€ 21.84$ & $€ 43.33$ & $€ 41.50$ & - \\
\hline Mullins et $\mathrm{al}^{35, d}$ & $\$ 93.40-\$ 98.60$ & $\$ 57.00-\$ 60.10$ & $\$ 99.40-\$ 115.70$ & $\$ 81.60-\$ 86.70$ & $\$ 86.50-\$ 90.60$ & $\$ 83.40-\$ 88.10$ & - \\
\hline Kelman and & $\$ 7,120$ & $\$ 8,167$ & $\$ 13,736$ & $\$ 7,427$ & $\$ 9,415$ & $\$ 9,096$ & - \\
\hline \multicolumn{8}{|l|}{ Von Seggern ${ }^{34, e}$} \\
\hline Ramsberg and & $€ 32.70$ & $€ 3 । .47$ & - & $€ 31.67$ & $€ 33.90$ & $€ 32.70$ & - \\
\hline \multicolumn{8}{|l|}{ Henriksson ${ }^{39, f}$} \\
\hline Asseburg et $\mathrm{al}^{12, g}$ & $€ 27.70$ & $€ 23.60$ & $€ 28.90$ & $€ 26.40$ & $€ 20.90$ & $€ 28.50$ & $€ 27.50$ \\
\hline
\end{tabular}

Notes: a Costs (2003-equivalent dollars) per pain-free patient at 2 hours; ${ }^{b}$ costs (2004-equivalent dollars) per successfully treated patient; 'costs (2004-equivalent euros) to render one sustained pain-free patient; ${ }^{d}$ costs (2006-equivalent dollars) per successfully treated attack, given as a range across seven US states, using Medicaid acquisition costs; ${ }^{\mathrm{e}}$ costs (2004-equivalent dollars) per 100 patients with sustained pain-free with no adverse events; ${ }^{\mathrm{f}}$ costs (20l0-equivalent euros) per patient with sustained pain-free attack with no adverse events; ${ }^{8}$ costs (euros, year not specified) per sustained pain-free attack with no adverse events; -, no data available.

Efficacy data were again taken from a previously published meta-analysis. ${ }^{40}$ Measures of effectiveness included a sustained pain-free status, which was defined as being pain-free at 2 hours postdose with no recurrence and no rescue medication for 2-24 hours. ${ }^{37}$ Costs included in the analysis were drug acquisition costs in addition to costs associated with the treatment of central nervous system- and chest-related adverse events. ${ }^{37}$ Cost-effectiveness for each triptan was evaluated in comparison with sumatriptan $100 \mathrm{mg} .{ }^{37}$ Combining clinical and economic considerations, rizatriptan $10 \mathrm{mg}$ and almotrip$\tan 12.5 \mathrm{mg}$ were demonstrated to be the most cost-effective triptans in Spain. ${ }^{37}$ Although this study is noteworthy for attempting to include the additional costs of treating adverse events, the costs associated with their management were estimated by clinical experts. Direct assessment of health care utilization costs would provide a more accurate accounting of the costs for treatment of adverse events.

Kelman and Von Seggern ${ }^{34}$ conducted a cost-effectiveness analysis of triptans, using the efficacy and tolerability data from the published meta-analysis,$^{30}$ using sumatriptan $100 \mathrm{mg}$ as the comparator. A successful outcome measure was described in terms of sustained pain-free plus no adverse events (SNAE). Costs per 100 SNAE patients were then calculated. This pharmacoeconomic study found that when using average wholesale prices, almotriptan $12.5 \mathrm{mg}(\$ 7,120)$, rizatriptan $10 \mathrm{mg}(\$ 7,427)$, followed by eletriptan $40 \mathrm{mg}(\$ 8,167)$ were the most cost-effective treatment options (Table 4).$^{34} \mathrm{~A}$ potential limitation of this study was that the calculation of SNAE was based on the assumption that efficacy and tolerability are uncorrelated. ${ }^{34}$
However, the actual association between efficacy and tolerability of triptans is unknown. Again, this analysis only assessed drug acquisition costs.

Mullins et $\mathrm{al}^{35}$ evaluated the pharmacoeconomics of six oral triptans (almotriptan, eletriptan, naratriptan, rizatriptan, sumatriptan, and zolmitriptan) from the perspective of Medicaid as a payor. Effectiveness data were again obtained from a previously published meta-analysis. ${ }^{30,40}$ Efficacy measures included: headache relief and pain-free at 2 hours, recurrence of headache pain, sustained pain-free, and recurrence.$^{35}$ Per dose acquisition costs were calculated using Medicaid reimbursement data from seven American states (Florida, Georgia, Illinois, North Carolina, Ohio, Wisconsin, and West Virginia). Among all marketed triptans across the seven states, eletriptan $20 \mathrm{mg}$ (range \$1,549-\$1,658) and eletriptan $40 \mathrm{mg}(\$ 1,578-\$ 1,661)$ exhibited the lowest costs to treat 100 migraine attacks. ${ }^{35}$ Naratriptan $2.5 \mathrm{mg}$ (range \$1,734-\$2,018), sumatriptan $25 \mathrm{mg}(\$ 1,853-\$ 1,954)$, and zolmitriptan $5 \mathrm{mg}(\$ 1,854-\$ 1,960)$ demonstrated the highest cost to treat 100 migraine attacks. ${ }^{35}$ Eletriptan $40 \mathrm{mg}$ exhibited the lowest cost/success (range \$57.00-\$60.10); naratriptan $2.5 \mathrm{mg}(\$ 99.40-\$ 115.70)$, sumatriptan $25 \mathrm{mg}$ (\$107.10-\$112.90 [data not shown]), and rizatriptan $5 \mathrm{mg}$ (\$99.40-\$111.30 [data not shown]) had the highest cost/ success values (Table 4). ${ }^{35}$ As with other pharmacoeconomic studies, this was an informal analysis that had not accounted for rescue medication costs, and only drug acquisition costs of nongeneric drugs were considered.

Ramsberg and Henriksson ${ }^{39}$ used a decision-tree costeffectiveness model to compare the costs and effects of five 
oral triptans (almotriptan, eletriptan, rizatriptan, sumatriptan, and zolmitriptan) in the treatment of a single attack in a typical migraine patient, from a Swedish societal perspective. Effectiveness data were again taken from a previously published meta-analysis. ${ }^{30,40}$ The primary end point was SNAE; other measures of efficacy included a status of pain-free at 2 hours and recurrence. ${ }^{39}$ Costs comprised drug acquisition costs and productivity losses. Additional sensitivity analyses were conducted using data from meta-analyses of the efficacy of triptans in the treatment of migraine conducted by Oldman et $\mathrm{al}^{41}$ and by Belsey. ${ }^{33}$ The results indicated that eletriptan $40 \mathrm{mg}$ and rizatriptan $10 \mathrm{mg}$ were the most cost-effective, with other triptans having higher costs and worse health outcomes (Table 4). ${ }^{39}$ Rizatriptan $10 \mathrm{mg}$ had an incrementally higher cost per SNAE of about $€ 100$ versus eletriptan $40 \mathrm{mg} .{ }^{39}$ Overall, rizatriptan $10 \mathrm{mg}$, eletriptan $40 \mathrm{mg}$, and almotriptan $12.5 \mathrm{mg}$ were more likely to be cost-effective than were the other three triptans assessed. ${ }^{39}$ This analysis did not compare triptans to no therapy or other nontriptan migraine treatments.

A recent independent cost-effectiveness/cost-utility analysis assessed all seven oral triptans following the introduction of generic sumatriptan to the Finnish market in 2008. ${ }^{12}$ In this study, the decision-tree model assessing oral triptans in Sweden ${ }^{39}$ was adapted to assess additional treatment arms and the related quality of life. Efficacy data were estimated from 56 publications following a systematic literature review and mixed treatment comparison. Efficacy measures included a response at 2 hours, a status of pain-free at 2 hours, and recurrence, with the primary efficacy end point being SNAE. ${ }^{12}$ Sustained pain-free at 24 hours and rescue medication were not considered. Cost-effectiveness was calculated as the incremental cost per additional SNAE. Secondarily, the incremental cost per quality-adjusted life year (QALY) gained was also estimated. QALYs were calculated based on utility values estimated from the Quality of Well-Being Scale, using utility weights estimated by Thompson et al..$^{42}$ The least costly treatment per attack was generic sumatriptan $100 \mathrm{mg}$ (€20.86). ${ }^{12}$ Overall, eletriptan $40 \mathrm{mg}$ was found to be the most cost-effective triptan in terms of the lowest incremental cost per additional SNAE. ${ }^{12}$ The incremental cost-effectiveness ratio of eletriptan $40 \mathrm{mg}$ relative to sumatriptan $100 \mathrm{mg}$ was about $€ 44$ per additional SNAE. ${ }^{12}$ The results for QALYs indicated that eletriptan $40 \mathrm{mg}$ had the greatest probability of being the most cost-effective option at willingness-to-pay thresholds of about $€ 20,000$ per QALY gained or above. ${ }^{12}$ In a one-way sensitivity analysis, the results were not sensitive to the costs of drug acquisition and utility values. ${ }^{12}$
Although this independent study derived efficacy data from a systematic review employing a mixed-treatment comparison, the application of the results might be limited because the authors did not evaluate the costs of health care service use or adverse event management. Another limitation is uncertainty regarding the utility estimates for the QALYs obtained from the study by Thompson et al. ${ }^{42}$ Non-preference-based measures were also employed to estimate quality of life.

Wells et $\mathrm{al}^{38}$ performed a cost-effectiveness analysis of eletriptan (40 mg and $80 \mathrm{mg}$ ) compared with sumatriptan (100 $\mathrm{mg}$ ), based on the results of a single randomized, doubleblind, placebo-controlled trial using two efficacy end points. The first efficacy measure, defined as "success measure 1", included 24-hour sustained pain-free with pain-free headache status at 2 hours, no recurrence within 24 hours of the first dosing, and no requirement for rescue medication; 38 "success measure 2" was defined as positive headache response at 1 hour and achievement of pain-free status by 2 hours. ${ }^{38}$ Costs included were drug acquisition costs, costs of a second dose, and the need for rescue medication. ${ }^{38}$ Costs per successfully treated attack were significantly lower for eletriptan $40 \mathrm{mg}$ versus sumatriptan $100 \mathrm{mg}$ using both efficacy outcome measures. Specifically, for success measure 1 , the costs per successfully treated migraine attack were $£ 17.55$ for eletriptan $40 \mathrm{mg}$ and $£ 80.50$ for sumatriptan $100 \mathrm{mg} .{ }^{38}$ Similarly, for success measure 2, costs were $£ 29.61$ for eletriptan $40 \mathrm{mg}$ and $£ 124.28$ for sumatriptan $100 \mathrm{mg}$ per successfully treated migraine attack. ${ }^{38}$ A major limitation of this study was that only one other triptan (sumatriptan) was included besides eletriptan, where the results were from a single clinical trial.

One recent study has used a classification and regression tree (CART) analysis to identify subpopulations of patients with migraine with a favorable cost profile for a given drug. ${ }^{43}$ In this study, a CART analysis was performed using propensity score-matched migraine populations treated with either eletriptan $40 \mathrm{mg}$ or generic sumatriptan $100 \mathrm{mg}$. Cost data used in the analyses were based on a retrospective Truven Health Analytics MarketScan ${ }^{\circledR}$ commercial claims and encounters database (Truven Health Analytics ${ }^{\circledR}$, Ann Arbor, MI, USA). CART analyses were used to determine variables relevant to the cost profile after initiating eletriptan, relative to generic sumatriptan. ${ }^{43}$ Health care costs were compared between eletriptan and generic sumatriptan for the stratified populations, by comparing the pre- to postindex differences in mean annual costs for the two triptans. ${ }^{43}$

The results of the CART analyses revealed that 1 year after the index date, total health care costs were comparable for eletriptan $40 \mathrm{mg}$ and generic sumatriptan $100 \mathrm{mg} .{ }^{43}$ 
However, in patients with higher health care utilization due to migraine, and in males, regardless of migraine severity, treatment with eletriptan $40 \mathrm{mg}$ had lower total costs versus generic sumatriptan $100 \mathrm{mg} .{ }^{43}$ Thus, for a certain subpopulation of migraine patients (males with higher health care utilization due to migraine), differences in annual health care costs were evident between eletriptan $40 \mathrm{mg}$ and sumatriptan $100 \mathrm{mg} .{ }^{43}$ Such differences in health care costs for a subpopulation raise the question of whether the cost-effectiveness of different triptans would also vary by subpopulation once the efficacy and tolerability of triptans in such subpopulations are incorporated in pharmacoeconomic models.

\section{Discussion}

In general, a consistent pattern of results emerged across the eight reviewed pharmacoeconomic studies: eletriptan $40 \mathrm{mg}$, rizatriptan $10 \mathrm{mg}$, and almotriptan $12.5 \mathrm{mg}$ were shown to be more cost-effective than other triptans. This pattern was evident when efficacy was defined as 2 hours pain-free, sustained painfree, and SNAE. Moreover, the pattern was evident when not only drug costs were included, but also, when cost-effectiveness models accounted for second doses of a triptan and use of rescue medication, ${ }^{38}$ management of adverse events, ${ }^{37}$ and productivity loss. ${ }^{12,39}$ In the most recent review of all seven triptans, which was independently conducted, eletriptan $40 \mathrm{mg}$ was found to be one of the most cost-effective treatment options, even in comparison with generic sumatriptan. ${ }^{12}$ Our findings in the current review are generally consistent with an earlier Canadian overview of pharmacoeconomic studies of triptans, which concluded that economic studies show that eletriptan, rizatriptan, and almotriptan were the most cost-effective triptans. ${ }^{44}$

One important consideration is the recurrence of migraine. Approximately $35 \%$ of patients who respond to treatment with a triptan experience a recurrence of headache within 24 hours..$^{30,40}$ However, in a pooled analysis of patients $(n=742)$ with multiple risk factors for suffering a recurrence of their migraine, Dodick et $\mathrm{al}^{45}$ found significantly lower recurrence rates with eletriptan $40 \mathrm{mg}$ versus sumatriptan $100 \mathrm{mg}$ (36\% versus 51\%, respectively) $(P<0.01)$. In addition, eletriptan $40 \mathrm{mg}$ has a favorable safety profile, ${ }^{30}$ and this in particular, likely enhanced the cost-effectiveness ratio, which incorporated adverse events.

Conclusions from this review need to be framed in terms of limitations of the available data. It should be noted that cost-effectiveness metrics were calculated, in most studies, using meta-analytic data summarizing placebo-controlled studies of triptans. Ideally, cost-effectiveness analyses would be based on direct head-to-head comparator studies involving all relevant agents. Only limited head-to-head comparator data were available, and only one single study compared all of the available triptans. ${ }^{12}$ The Ramsberg and Henriksson study included a secondary analysis focusing only on comparator trials, but none of the four comparator trials examined included eletriptan. ${ }^{39} \mathrm{~A}$ related concern is that six of the eight available pharmacoeconomic studies ${ }^{12,34-37,39}$ relied primarily or exclusively on the same meta-analysis ${ }^{30}$ for efficacy and/ or tolerability data. Future cost-effectiveness evaluations of triptans should incorporate updated efficacy/tolerability data, with more comparator trials, for computing cost-effectiveness ratios. Another important limitation is that the majority of the available studies did not include indirect costs in their pharmacoeconomic analysis.

It is also important to note that since the publication of some of the pharmacoeconomic studies reviewed here, additional generic versions of most of the triptans are now available. However, as noted earlier in this review, drug acquisition costs only make up a small portion of the total annual cost burden of migraine, even when triptan therapy is limited to prescription drugs. Because of the limited impact of drug costs, it is likely that eletriptan $40 \mathrm{mg}$ remains a cost-effective option even when compared with triptans that are now available as generics. However, confirmation of the cost-effectiveness of eletriptan relative to generic triptans would require data from prospective, head-to-head migraine trials that include valid and current assessments of direct and indirect costs.

\section{Conclusion}

With these limitations in mind, the results of available studies consistently found eletriptan $40 \mathrm{mg}$ was among the most clinically and cost-effective of the oral triptans for the treatment of acute migraine. This finding was evident across diverse countries and payers, including Medicaid in the USA.

\section{Acknowledgments}

Editorial support was provided by Sarah Knott of Engage Scientific and funded by Pfizer Inc. Additional support, composed of copyediting a late draft of the manuscript and collating authors' responses to peer review comments, was provided by Anne Jakobsen, MSc; Abegale Templar, PhD; and Jon Edwards, PhD, of Engage Scientific and funded by Pfizer Inc.

\section{Disclosure}

The study was funded by Pfizer Inc. Drs Bhambri, Mardekian, Liu, and Ramos are full-time employees of Pfizer Inc. 
Dr Schweizer owns stock in Pfizer Inc. and Novartis, and has received payments for consulting and/or medical writing services from Alkermes, Sunovion Pharmaceuticals, Titan Pharmaceuticals, Novartis AG, and Pfizer Inc. Dr Schweizer is also the owner of Paladin Consulting Group, Inc., which was a paid consultant to Pfizer Inc. in connection with the development of this manuscript. The authors report no other conflicts of interest.

\section{References}

1. Headache Classification Committee of the International Headache Society (IHS). The International Classification of Headache Disorders, 3rd edition (beta version). Cephalalgia. 2013;33(9):629-808.

2. Lipton RB, Scher AI, Kolodner K, Liberman J, Steiner TJ, Stewart WF. Migraine in the United States: epidemiology and patterns of health care use. Neurology. 2002;58(6):885-894.

3. McCormack PL, Keating GM. Eletriptan: a review of its use in the acute treatment of migraine. Drugs. 2006;66(8):1129-1149.

4. Lipton RB, Bigal ME, Diamond M, Freitag F, Reed ML, Stewart WF; AMPP Advisory Group. Migraine prevalence, disease burden, and the need for preventive therapy. Neurology. 2007;68(5):343-349.

5. Von Korff M, Stewart WF, Simon DJ, Lipton RB. Migraine and reduced work performance: a population-based diary study. Neurology. 1998;50(6):1741-1745.

6. Lipton RB, Diamond S, Reed M, Diamond ML, Stewart WF. Migraine diagnosis and treatment: results from the American Migraine Study II. Headache. 2001;41(7):638-645.

7. Buse DC, Lipton RB. Global perspectives on the burden of episodic and chronic migraine. Cephalalgia. 2013;33(11):885-890.

8. Goldstein J, Tiseo PT, Albert KS, Li C, Sikes CR. Eletriptan in migraine patients reporting unsatisfactory response to rizatriptan. Headache. 2006;46(7):1142-1150.

9. Aukerman G, Knutson D, Miser WF; Department of Family Medicine, Ohio State University College of Medicine and Public Health, Columbus, Ohio. Management of the acute migraine headache. Am Fam Physician. 2002;66(11):2123-2130.

10. Olesen J, Burstein R, Ashina M, Tfelt-Hansen P. Origin of pain in migraine: evidence for peripheral sensitisation. Lancet Neurol. 2009;8(7):679-690.

11. Caro JJ, Getsios D. Pharmacoeconomic evidence and considerations for triptan treatment of migraine. Expert Opin Pharmacother. 2002;3(3): 237-248.

12. Asseburg C, Peura P, Oksanen T, Turunen J, Purmonen T, Martikainen J. Cost-effectiveness of oral triptans for acute migraine: mixed treatment comparison. Int J Technol Assess Health Care. 2012;28(4): 382-389.

13. Lamb CE, Ratner PH, Johnson CE, et al. Economic impact of workplace productivity losses due to allergic rhinitis compared with select medical conditions in the United States from an employer perspective. Curr Med Res Opin. 2006;22(6):1203-1210.

14. Lipton RB, Stewart WF, Scher AI. Epidemiology and economic impact of migraine. Curr Med Res Opin. 2001;17 Suppl 1:S4-S12.

15. Stang PE, Osterhaus JT. Impact of migraine in the United States: data from the National Health Interview Survey. Headache. 1993;33(1): 29-35.

16. de Lissovoy G, Lazarus SS. The economic cost of migraine. Present state of knowledge. Neurology. 1994;44(6 Suppl 4):S56-S62.

17. Dueland AN, Leira R, Burke TA, Hillyer EV, Bolge S. The impact of migraine on work, family, and leisure among young women a multinational study. Curr Med Res Opin. 2004;20(10):1595-1604.

18. Hu XH, Markson LE, Lipton RB, Stewart WF, Berger ML. Burden of migraine in the United States: disability and economic costs. Arch Intern Med. 1999;159(8):813-818.
19. Linde M, Gustavsson A, Stovner LJ, et al. The cost of headache disorders in Europe: the Eurolight project. Eur J Neurol. 2012;19(5):703-711.

20. Goldberg LD. The cost of migraine and its treatment. Am J Manag Care. 2005;11(Suppl 2):S62-S67.

21. Goadsby PJ, Ferrari MD, Olesen J, et al. Eletriptan in acute migraine: a double-blind, placebo-controlled comparison to sumatriptan. Eletriptan Steering Committee. Neurology. 2000;54(1):156-163.

22. Mathew NT, Schoenen J, Winner P, Muirhead N, Sikes CR Comparative efficacy of eletriptan $40 \mathrm{mg}$ versus sumatriptan $100 \mathrm{mg}$. Headache. 2003;43(3):214-222.

23. Sandrini G, Färkkilä M, Burgess G, Forster E, Haughie S; Eletriptan Steering Committee. Eletriptan vs sumatriptan: a double-blind, placebocontrolled, multiple migraine attack study. Neurology. 2002;59(8): $1210-1217$.

24. Garcia-Ramos G, MacGregor EA, Hilliard B, Bordini CA, Leston J, Hettiarachchi J. Comparative efficacy of eletriptan vs naratriptan in the acute treatment of migraine. Cephalalgia. 2003;23(9):869-876.

25. Steiner TJ, Diener HC, MacGregor EA, Schoenen J, Muirheads N, Sikes CR. Comparative efficacy of eletriptan and zolmitriptan in the acute treatment of migraine. Cephalalgia. 2003;23(10):942-952.

26. Färkkilä M, Olesen J, Dahlöf C, et al. Eletriptan for the treatment of migraine in patients with previous poor response or tolerance to oral sumatriptan. Cephalalgia. 2003;23(6):463-471.

27. Chia YC, Lim SH, Wang SJ, Cheong YM, Denaro J, Hettiarachchi J. Efficacy of eletriptan in migraineurs with persistent poor response to nonsteroidal anti-inflammatory drugs. Headache. 2003;43(9):984-990.

28. Diamond ML, Hettiarachchi J, Hilliard B, Sands G, Nett R. Effectiveness of eletriptan in acute migraine: primary care for Excedrin nonresponders. Headache. 2004;44(3):209-216.

29. Martin VT, Loder E, Taylor K, Almas M, Hilliard B. Eletriptan treatment of migraine in patients switching from barbiturate-containing analgesics: results from a multiple-attack study. Cephalalgia. 2005;25(9):726-734.

30. Ferrari MD, Goadsby PJ, Roon KI, Lipton RB. Triptans (serotonin, 5-HT1B/1D agonists) in migraine: detailed results and methods of a meta-analysis of 53 trials. Cephalalgia. 2002;22(8):633-658.

31. Thorlund K, Mills EJ, Wu P, et al. Comparative efficacy of triptans for the abortive treatment of migraine: a multiple treatment comparison meta-analysis. Cephalalgia. 2014;34(4):258-267.

32. Relpax (eletriptan hydrobromide) tablet, film coated [prescribing information]. New York, NY: Pfizer Inc.; 2013. Available from: http://labeling. pfizer.com/ShowLabeling.aspx?id=621. Accessed July 31, 2014.

33. Belsey JD. Cost effectiveness of oral triptan therapy: a trans-national comparison based on a meta-analysis of randomised controlled trials. Curr Med Res Opin. 2004;20(5):659-669.

34. Kelman L, Von Seggern RL. Using patient-centered endpoints to determine the cost-effectiveness of triptans for acute migraine therapy. Am J Ther. 2006;13(5):411-417.

35. Mullins CD, Subedi PR, Healey PJ, Sanchez RJ. Economic analysis of triptan therapy for acute migraine: a Medicaid perspective. Pharmacotherapy. 2007;27(8):1092-1101.

36. Perfetto EM, Weis KA, Mullins CD, Subedi P, Healey PJ Sr. An economic evaluation of triptan products for migraine. Value Health 2005;8(6):647-655.

37. Slof J, Badia X, Lainez-Andres JM, Galvan J, Heras J. [Management costs of chest and CNS-related adverse events associated with the treatment of acute migraine attacks with oral triptans]. Neurologia. 2005;20(6):290-298. Spanish.

38. Wells N, Hettiarachchi J, Drummond M, et al. A cost-effectiveness analysis of eletriptan 40 and $80 \mathrm{mg}$ versus sumatriptan 50 and $100 \mathrm{mg}$ in the acute treatment of migraine. Value Health. 2003;6(4):438-447.

39. Ramsberg J, Henriksson M. The cost-effectiveness of oral triptan therapy in Sweden. Cephalalgia. 2007;27(1):54-62.

40. Ferrari MD, Roon KI, Lipton RB, Goadsby PJ. Oral triptans (serotonin 5-HT(1B/1D) agonists) in acute migraine treatment: a meta-analysis of 53 trials. Lancet. 2001;358(9294):1668-1675. 
41. Oldman AD, Smith LA, McQuay HJ, Moore RA. Pharmacological treatments for acute migraine: quantitative systematic review. Pain. 2002;97(3):247-257.

42. Thompson M, Gawel M, Desjardins B, Ferko N, Grima D. An economic evaluation of rizatriptan in the treatment of migraine. Pharmacoeconomics. 2005;23(8):837-850.

43. Ramos E, Liu L, Mardekian J, Cabrera J. Identification of subpopulations of migraine patients who have a favorable cost profile with eletriptan treatment. Cephalalgia. 2013;33(8):148-149.
44. Membe S, McGahan L, Cimon K, Gawel M, Giammarco R, Mierzwinski-Urban M. Technology Report: Triptans for Acute Migraine: Comparative Clinical Effectiveness and Cost-Effectiveness. Ottawa, ON: Canadian Agency for Drugs and Technologies in Health; 2007. Available from: http://www.cadth.ca/media/pdf/I4001_tr_Triptans_e. pdf. Accessed July 29, 2014.

45. Dodick DW, Lipton RB, Goadsby PJ, et al. Predictors of migraine headache recurrence: a pooled analysis from the eletriptan database. Headache. 2008;48(2):184-193.

\section{Publish your work in this journal}

The International Journal of General Medicine is an international, peer-reviewed open-access journal that focuses on general and internal medicine, pathogenesis, epidemiology, diagnosis, monitoring and treatment protocols. The journal is characterized by the rapid reporting of reviews, original research and clinical studies across all disease areas.
A key focus is the elucidation of disease processes and management protocols resulting in improved outcomes for the patient.The manuscript management system is completely online and includes a very quick and fair peer-review system. Visit http://www.dovepress.com/ testimonials.php to read real quotes from published authors. 